\title{
Mechanical Behavior, Energy Release, and Crack Distribution Characteristics of Water-Saturated Phyllite under Triaxial Cyclic Loading
}

\author{
Yang Zhou (D), Shengrui Su $(\mathbb{D}$, and Peng Li \\ School of Geological Engineering and Geomatics, Chang'an University, Xi'an 710064, China \\ Correspondence should be addressed to Shengrui Su; shengruisu@163.com
}

Received 28 July 2021; Revised 17 October 2021; Accepted 26 November 2021; Published 30 December 2021

Academic Editor: Guowen Xu

Copyright (c) 2021 Yang Zhou et al. This is an open access article distributed under the Creative Commons Attribution License, which permits unrestricted use, distribution, and reproduction in any medium, provided the original work is properly cited.

\begin{abstract}
Many geological engineering hazards are closely related to the dynamic mechanical behaviors of rock materials. However, the dynamic mechanical behaviors of phyllite are less studied. In this study, we have carried out a series of triaxial cyclic tests on dry and water-saturated phyllite by employing the MTS 815 servohydraulic testing system and AE testing equipment to reveal the mechanical behavior, energy release, and crack distribution characteristics of phyllite. Results show that phyllite is a watersensitive rock. Water and cyclic loading substantially affect the compressive strength, crack damage stress, deformation parameters, dilatancy, energy release, and crack distribution characteristics of phyllite. Furthermore, based on the dissipated energy, a new damage variable for phyllite is established. The critical damage variable for phyllite is approximately 0.80 ; this variable can be used as an index to predict the failure of phyllite. The water saturation effect of phyllite is very obvious; that is, it results in the weakness of mechanical properties of phyllite and changes the AE energy release and crack distribution characteristics of phyllite. This research can provide guidance for engineering construction and disaster prevention and control.
\end{abstract}

\section{Introduction}

Rock mass is often affected by mechanical excavation, blasting, earthquake, and other dynamic loads in engineering activities. The mechanical properties of rock materials under dynamic loading have a significant influence on engineering activities. Many geological engineering hazards (such as slope instability, cave collapse, and large deformation of surrounding rock) are closely related to the dynamic mechanical behaviors of rock materials. Therefore, it is of great significance to study the effect of dynamic loading on the mechanical behaviors and failure mechanism of rock materials for engineering construction and disaster prevention and control.

When tunnels and slopes are excavated, the rock mass undergoes very complicated stress path owing to the layered, segmented excavation and excavation between adjacent caverns. The rock mass is in a state of cyclic loading and unloading. Once the stress exceeds the ultimate bearing capacity of the rock mass, geological engineering hazards may occur; these pose a great threat to the safety of engineering and field staff. At present, considerable research has been conducted on the mechanical behaviors of rocks under cyclic loading. Fuenkajorn and Phueakphum [1] studied the effect of cyclic loading on compressive strength and elastic modulus of rock salt. Duan and Yang [2] studied the fatigue deformation of sandstone under uniaxial cyclic loading and found that the energy dissipation curve can reflect the fatigue deformation of the sandstone. Liu et al. [3] studied the mechanical behaviors of intermittently jointed rock models under uniaxial cyclic loading. Xiao et al. [4] studied the damage evolution of sandstone under cyclic loading and found the three-stage evolution process of the damage. Fan et al. [5] conducted a series of discontinuous cyclic loading tests and studied the fundamental role of the loading history in the fatigue performance of salt. Sheng et al. [6] studied the mechanical damage characteristics of sandstone under triaxial cyclic loading. Ning et al. [7] studied the crack 
initiation and propagation thresholds of coal specimens based on energy dissipation theory. The mechanical behaviors of rocks are closely related to the stress path, confining pressure, moisture condition, and rock type. However, the mechanical properties, energy release, and crack distribution characteristics of water-saturated rock materials under cyclic loading are less studied.

Phyllite is a type of metamorphic rock that is widely distributed on the surface of the Earth and is used for many engineering activities. During construction and later operation, the mechanical properties of phyllite directly affect the safety and stability of project. To date, many achievements have been made regarding the static mechanical properties of phyllite [8-15]. However, the mechanisms of damage, deformation, and failure of saturated phyllite under cyclic loading are still unclear. This study focuses on the mechanical behaviors and AE characteristics of dry and saturated phyllite under the influence of confining pressure and cyclic loading. The deformation parameters, dilatancy characteristic, damage stress, and damage variable of phyllite under confining pressures of 5, 10 , and $20 \mathrm{MPa}$ were analyzed. Degradation mechanism of water-saturated phyllite was discussed, and the energy release and crack distribution characteristics were revealed. The research results can provide guidance for the safe construction of slopes, tunnels, and foundations, as well as disaster prevention.

\section{Materials and Methods}

In this paper, slightly weathered phyllite obtained from the northwest part of Sichuan Province, China, was used as the research object. This phyllite is composed of quartz, plagioclase, calcite, mica, and chlorite. The average density and $\mathrm{P}$-wave velocity of phyllite were $2.70 \mathrm{~g} / \mathrm{cm}^{3}$ and $2.48 \mathrm{~km} / \mathrm{s}$, respectively. According to the recommendations of the International Society of Rock Mechanics (ISRM), the phyllite was processed into $\varnothing 50 \times 100 \mathrm{~mm}$ cylindrical specimens. The bedding plane of the phyllite specimen was nearly horizontal. The two ends of the specimens were polished. P-wave velocities and densities of all specimens were measured to remove the outliers. Selected specimens were placed in an oven with a constant temperature of $105^{\circ} \mathrm{C}$ until the mass was constant. At that time, the specimens were considered to be dry. Half of the dry specimens were first vacuumed for $8 \mathrm{~h}$ using vacuum pumping and then placed in an aqueous solution for $48 \mathrm{~h}$; after this, the specimens were considered to be saturated. Before testing, the water-saturated specimens were placed in fresh-keeping bags to prevent water evaporation. The uniaxial compressive strength of the phyllite was approximately $75 \mathrm{MPa}$, and the elastic modulus and Poisson's ratio were approximately $22 \mathrm{GPa}$ and 0.18 , respectively. A series of cyclic loading and unloading tests were carried out using the MTS 815 servohydraulic testing system (Figure 1). The PCI-2 monitoring system produced by the American Physical Acoustics Corporation was used for the AE testing. Eight AE sensors were installed on the surface of the sample chamber to collect the AE signals (Figure 1).
Triaxial cyclic loading and unloading tests were conducted and controlled using axial displacement loading and axial stress unloading. The loading rate of axial displacement was $0.005 \mathrm{~mm} / \mathrm{s}$ and the unloading rate of axial stress was $0.5 \mathrm{MPa} / \mathrm{s}$. The triaxial cyclic loading and unloading tests were performed under confining pressures of 5,10 , and $20 \mathrm{MPa}$. First, the triaxial confining pressures were applied to the predetermined levels $(5,10$, and $20 \mathrm{MPa})$ at a rate of $0.5 \mathrm{MPa} / \mathrm{s}$. Second, the confining pressure remained constant. The axial displacement was first loaded to $0.3 \mathrm{~mm}$ at a rate of $0.005 \mathrm{~mm} / \mathrm{s}$; then, the axial deviatoric stress was unloaded to $0.5 \mathrm{MPa}$ at a rate of $0.5 \mathrm{MPa} / \mathrm{s}$. Third, the loading and unloading cycles were carried out at $0.03 \mathrm{~mm}$ axial displacement interval. The triaxial cyclic loading and unloading tests were continued until the phyllite specimens failed.

\section{Results}

3.1. Stress-Strain Curves. The loading and unloading curves cannot coincide completely under triaxial cyclic loading (Figure 2). The loading curve is always above the unloading curve. Phyllite is a heterogeneous material that contains microcracks. Owing to the sliding and closing of the cracks during the loading process, the unloading curve cannot completely return to its original shape. The loading and unloading curves form a hysteresis loop. Hysteresis loops are sparse in the first several cycles and then densely distributed for a long time. When the rock specimen approaches failure, the hysteresis loops become sparse again. Each hysteresis loop consists of elastic strain and plastic strain. The elastic strain can be recovered during the unloading process, whereas the plastic strain is irreversible. With an increase in the number of cycles, the plastic strain accumulates until the specimen fails. In addition, the compressive strength of saturated phyllite is obviously lower than that of dry phyllite. Phyllite is a type of water-sensitive rock.

3.2. Deformation Parameters. The strain, elastic modulus, and Poisson's ratio are important deformation parameters of rock. Phyllite is a heterogeneous material that retains its residual strain (irreversible strain) after unloading. The calculation method for the irreversible strain is shown in Figure 3. In general, with the increase of axial stress, the irreversible strain increases exponentially under different confining pressures (Figure 4). During the early loading process, the axial and radial irreversible strains increase at a relatively stable rate. When the phyllite approaches failure, the irreversible strain increases rapidly, leading to the sudden failure of the phyllite specimen. When the axial stresses are the same, the axial and lateral irreversible strains of saturated phyllite are significantly larger than those of dry phyllite. With the increase in axial stress, the difference in irreversible strain between saturated phyllite and dry phyllite increases gradually. Water has a significant effect on the axial and lateral irreversible strain of phyllite. The softening effect of water on phyllite leads to an increase in the plastic deformation. In addition, when the axial stresses are the same, 


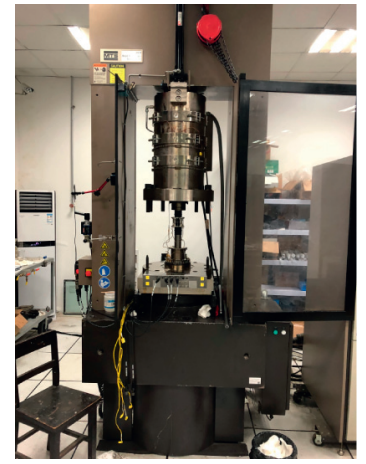

(a)

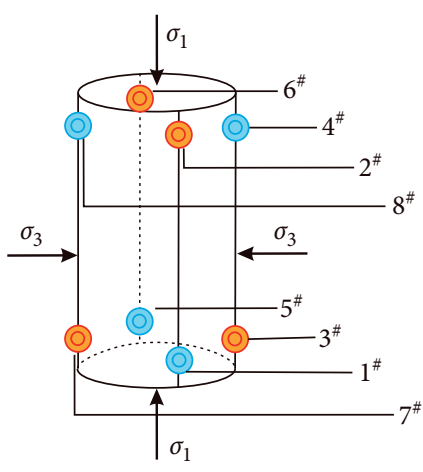

(b)

FIGURE 1: Experimental instruments: (a) MTS 815 servohydraulic testing system and (b) sketch of AE sensors arrangement.

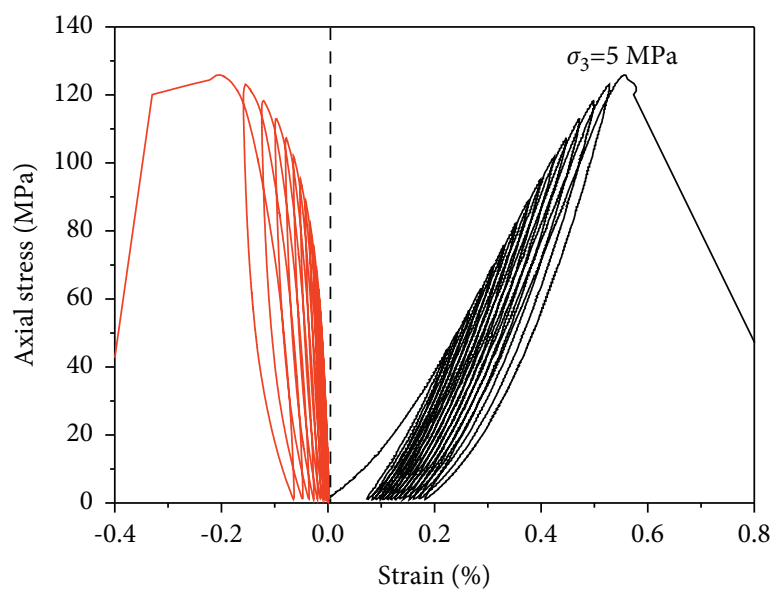

- Axial strain

— Radial strain

(a)

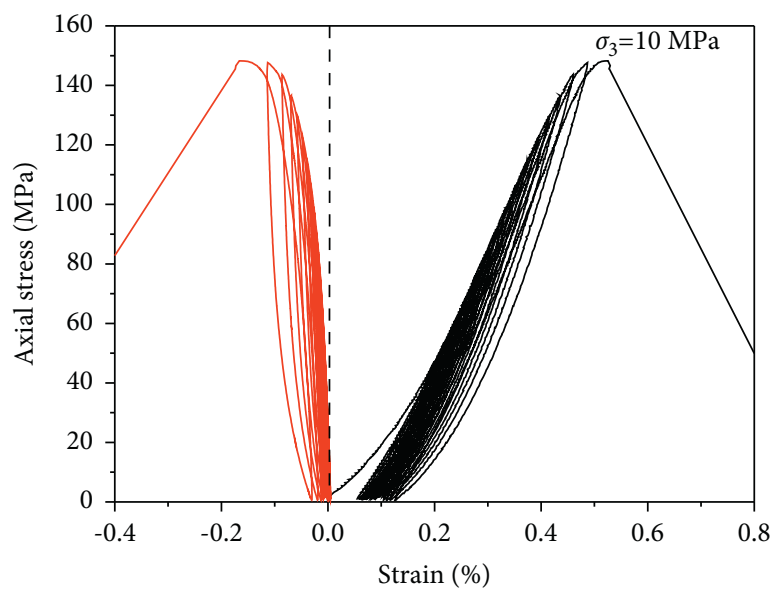

— Axial strain
Radial strain

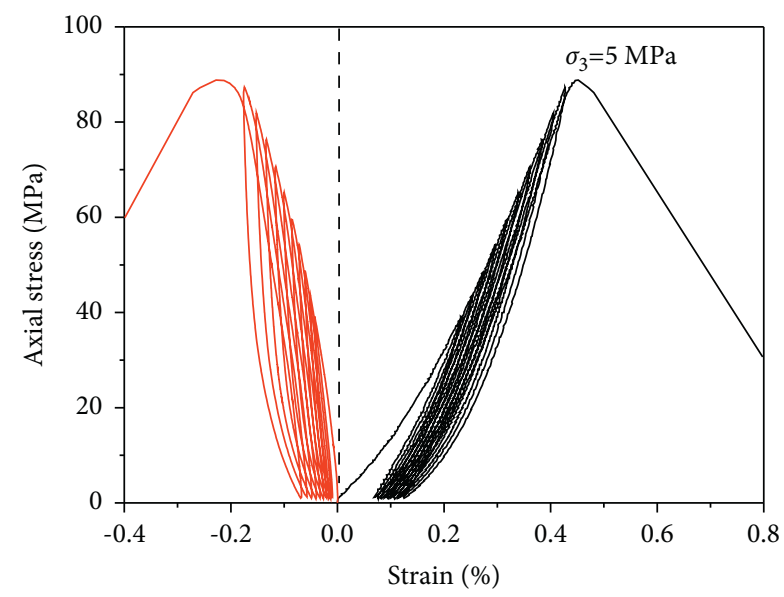

— Axial strain

— Radial strain

(b)

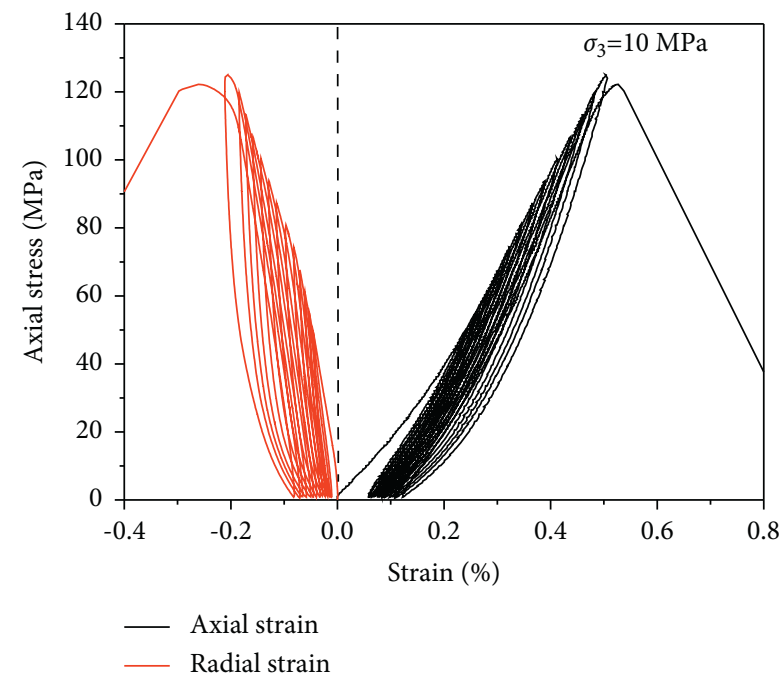

(d)

FIgURE 2: Continued. 


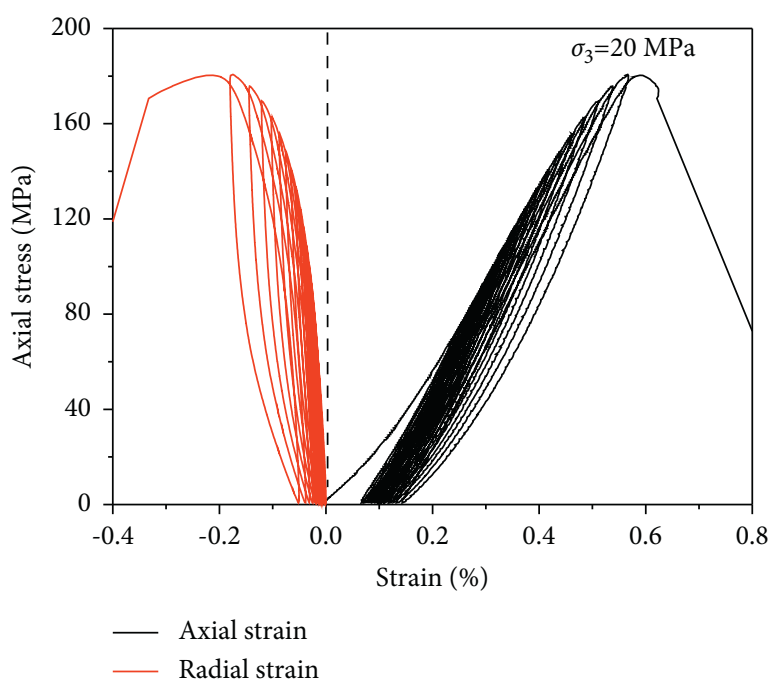

(e)

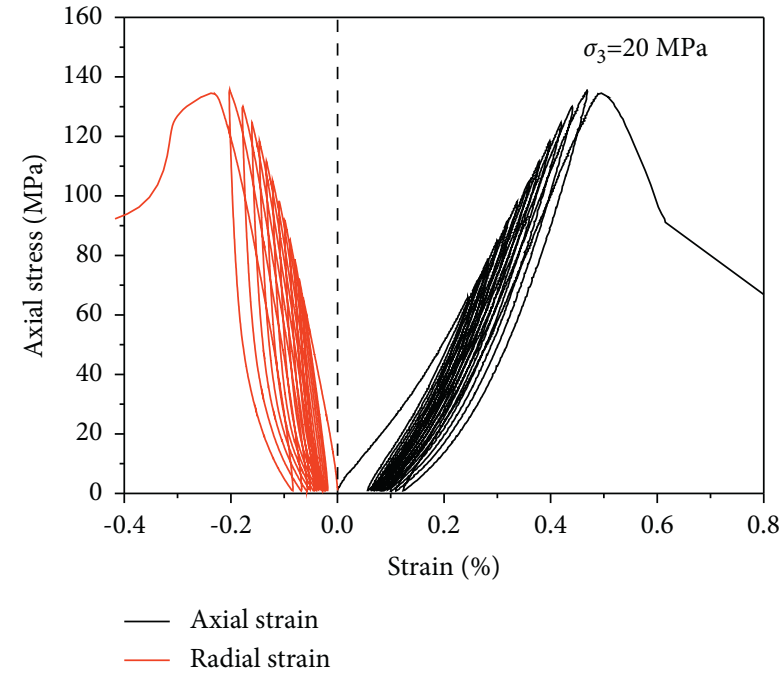

(f)

FIGURE 2: Stress-strain curves of phyllite under triaxial cyclic loading ( $\sigma_{3}$ is the confining pressure). (a) Dry sample. (b) Saturated sample. (c) Dry sample. (d) Saturated sample. (e) Dry sample. (f) Saturated sample.

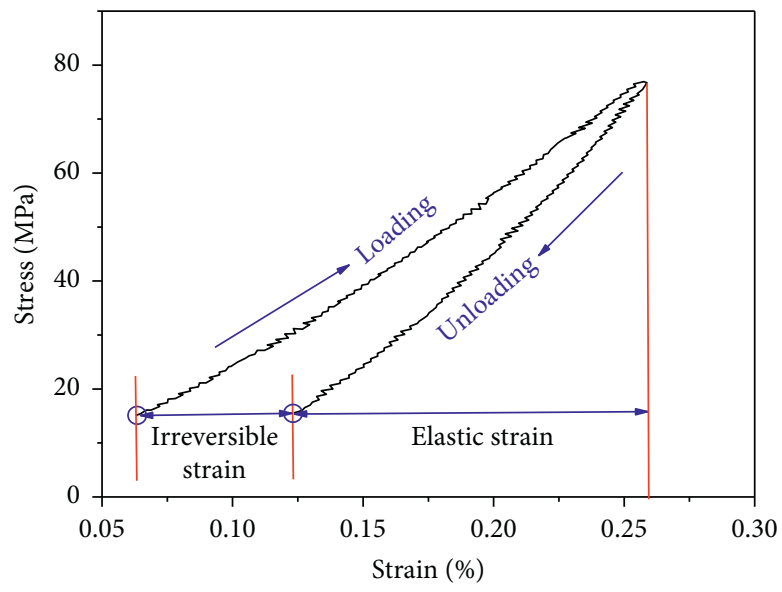

FIGURE 3: Sketch of irreversible strain.

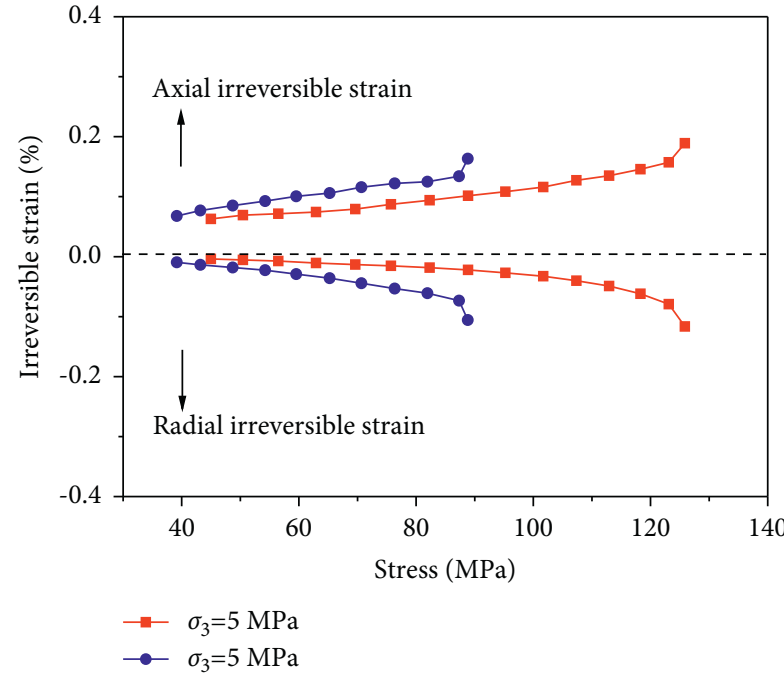

(a)

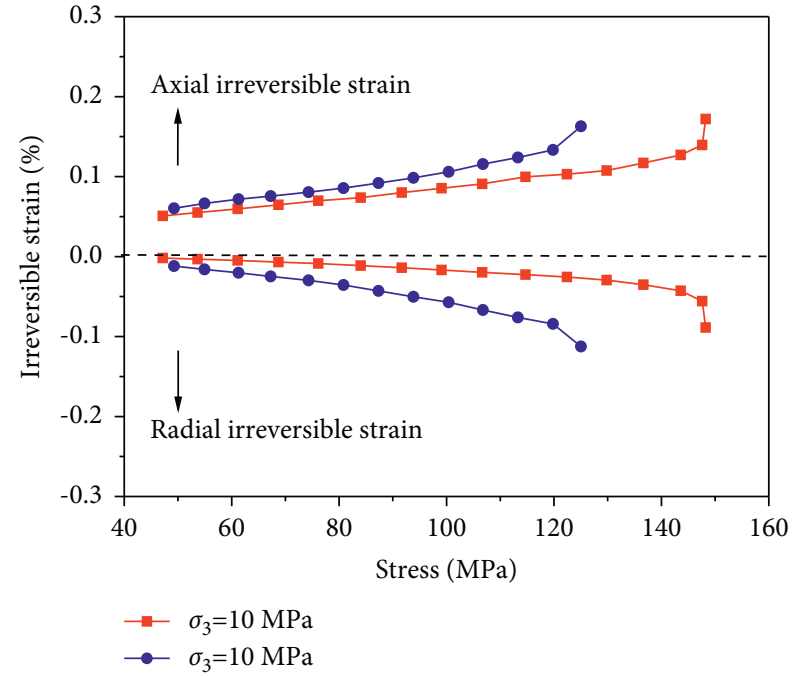

(b)

Figure 4: Continued. 


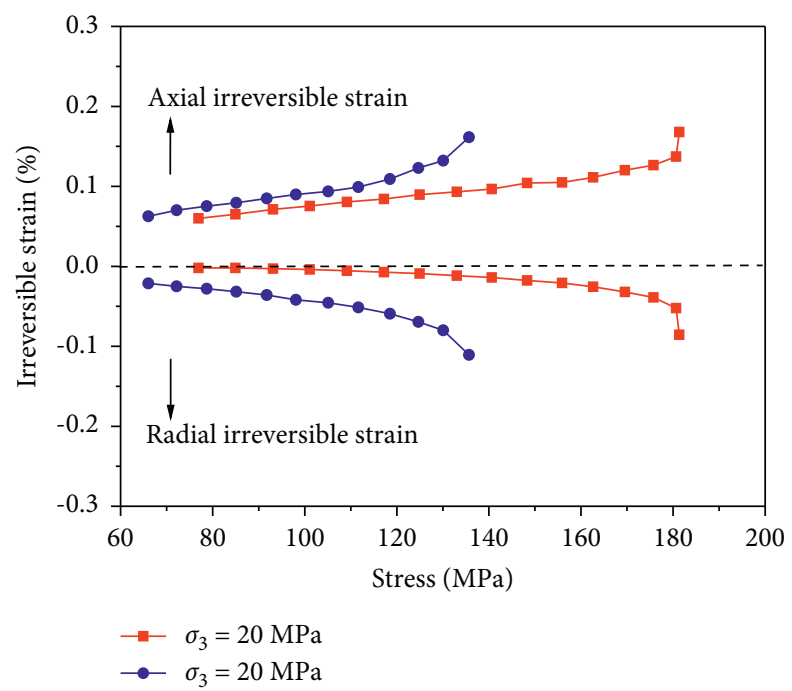

(c)

FIGURE 4: Relationship between irreversible strains and axial stress (blue denotes saturated phyllite and red denotes dry phyllite; $\sigma_{3}$ is the confining pressure).

the axial and radial irreversible strains decrease with an increase in the confining pressure.

The straight parts of the loading curves were calculated to study the change law of the elastic modulus during cyclic loading. Figure 5 shows that the first loading has an obvious strengthening effect on phyllite, and the elastic modulus is greatly improved. With the increase of confining pressure, the elastic modulus of phyllite increases. The confining pressure improves the friction between crack surfaces, hinders the crack propagation and sliding, and improves the strength and elastic modulus of phyllite. The elastic modulus of dry phyllite is obviously larger than that of saturated phyllite. It may be that the softening effect of water reduces the ability of phyllite to resist deformation. Compared with confining pressure and water, the effect of the loading paths on the elastic modulus is more significant. With an increase in the number of cycles, the elastic modulus first increases, then tends to be constant, and finally decreases. The variation in the elastic modulus of phyllite is the same as that of gypsum [16]. That is because the preexisting microcracks in phyllite close, and the elastic modulus increases during the early cyclic loading. Then, the modulus is basically unchanged or increases slowly, a process which actually represents the competition between crack expansion and particle compaction. During the loading and unloading process, on the one hand, the disordered expansion microcracks in phyllite reduce the stiffness and modulus of the specimen. On the other hand, the mineral particles formed by crack cutting are recompacted, and the fracture is filled with detritus, which improves the stiffness and modulus of phyllite. The elastic modulus of phyllite remains constant or increases slowly under the influence of these two factors. During the last few cycles, the expansion cracks propagate and gather rapidly, and the elastic modulus decreases. However, the results of this study differ from those of Western granite and Etna basalt [16-18]. With an increase in cycles, the elastic moduli of granite and basalt decrease. There is a significant difference between the elastic moduli of soft rock and hard rock under cyclic loading. This may be related to internal factors such as mineral composition and cementation type. Therefore, the expansion and distribution of cracks and the deformation characteristics of mineral particles under cyclic loading are the key to exploring the difference between the elastic moduli of soft rock and hard rock, which is worthy of further study.

Poisson's ratio of phyllite increases with an increase in cycles (Figure 5). This is because of the rapid increase in the lateral deformation (including crack expansion and fracture plane slip) during cyclic loading. In addition, Poisson's ratio of phyllite is very sensitive to water. Poisson's ratio of the saturated phyllite is almost twice that of dry phyllite. When the confining pressure is $5 \mathrm{MPa}$, the maximum Poisson's ratio of the saturated phyllite is 0.45 . This is because phyllite contains clay minerals. The softening effect of water on phyllite promotes the lateral expansion. In addition, water reduces the friction coefficient between microcracks, which is conducive to the initiation and expansion of cracks and the sliding of fracture planes. This promotes an increase in Poisson's ratio.

3.3. Dilatancy Characteristics. The volume strain curves are shown in Figure 6. During the early cyclic loading (low stress level), the hysteresis loops are very narrow and dense. With the increase of cycles (high stress level), the hysteresis loops become wider, and the volume curves become sparse, which indicates that the volume of phyllite gradually changed from compaction-dominated to expansion-dominated. The confining pressure clearly inhibits the volume expansion of the phyllite. Furthermore, the volume expansion of saturated phyllite is different from that of dry phyllite. For example, when the confining pressure was $5 \mathrm{MPa}$, the volume of 


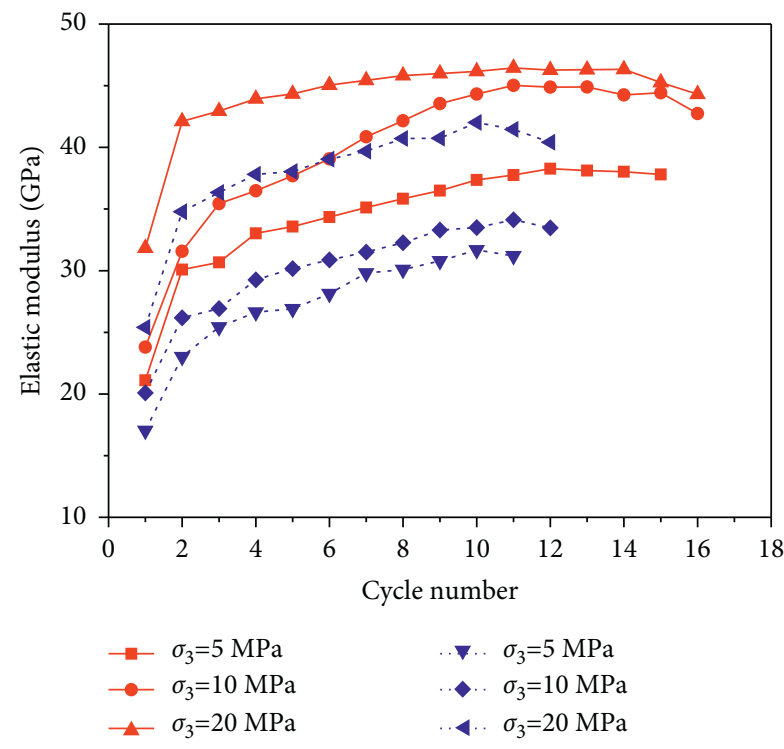

(a)

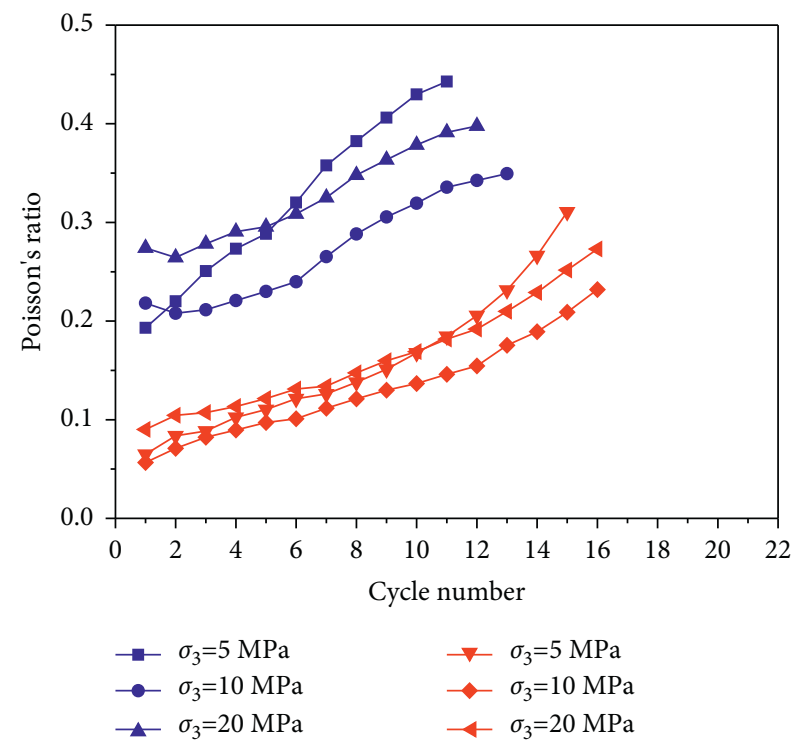

(b)

Figure 5: Elastic modulus and Poisson's ratio (blue denotes saturated phyllite and red denotes dry phyllite; $\sigma_{3}$ is the confining pressure): (a) elastic modulus and (b) Poisson's ratio.

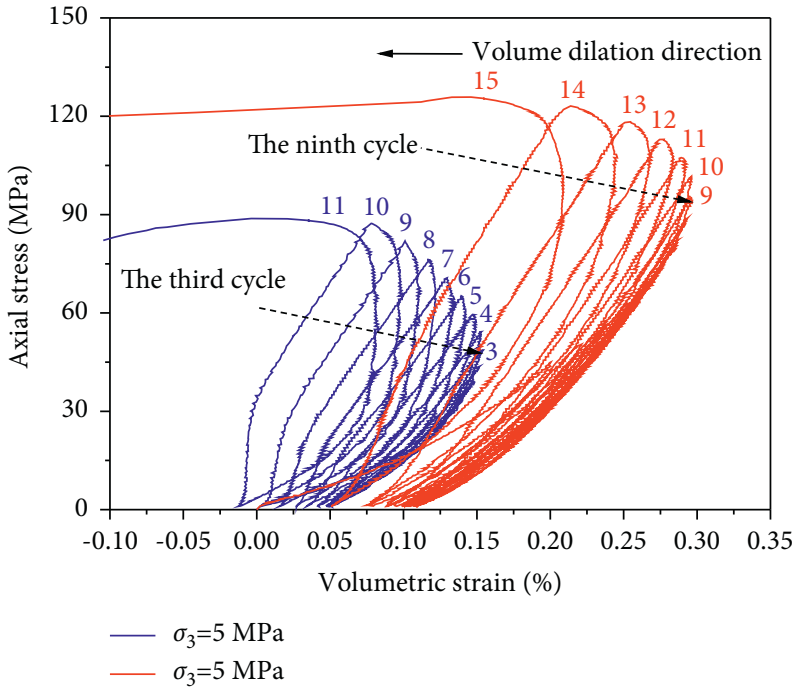

(a)

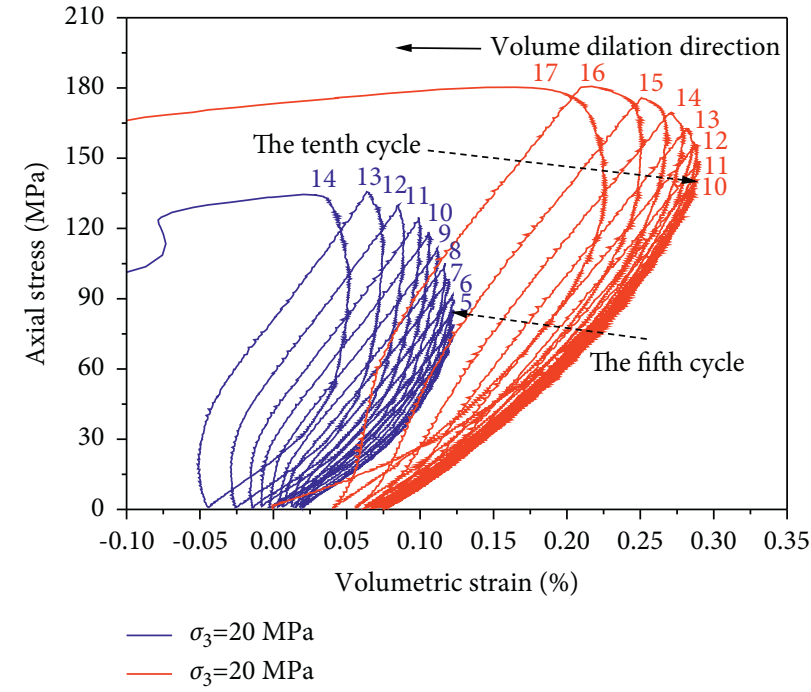

(b)

Figure 6: Typical volumetric strain of phyllite (blue denotes saturated phyllite and red denotes dry phyllite; $\sigma_{3}$ is the confining pressure).

saturated phyllite changed from compaction-dominated to expansion-dominated in the third cycle, with a critical volume strain of 0.15 . However, the volume of dry phyllite changed from compaction-dominated to expansion-dominated in the ninth cycle, with a critical volume of is 0.30 . When the confining pressure was $20 \mathrm{MPa}$, the volume of saturated phyllite changed from compaction-dominated to expansion-dominated in the fifth cycle, with a critical volume strain of 0.12 . However, the volume of dry phyllite changed from compaction-dominated to expansion-dominated in the tenth cycle, with a critical volume strain of 0.29. Compared with dry phyllite, the volume expansion of saturated phyllite starts earlier, and the compression deformation before volume expansion is smaller. Water accelerates the change of volume from compaction to expansion.

The stress-strain curves of rock materials in a triaxial compression test can be roughly divided into five stages (Figure 7): crack closure stage (I), elastic stage (II), stable crack growth stage (III), unstable crack growth stage (IV), and postpeak stage $(\mathrm{V})$. Crack damage stress $\left(\sigma_{\mathrm{cd}}\right)$ can be identified from laboratory test. Crack damage stress is the dividing point between stable crack growth stage and unstable crack growth stage. When the axial stress exceeds the crack damage 


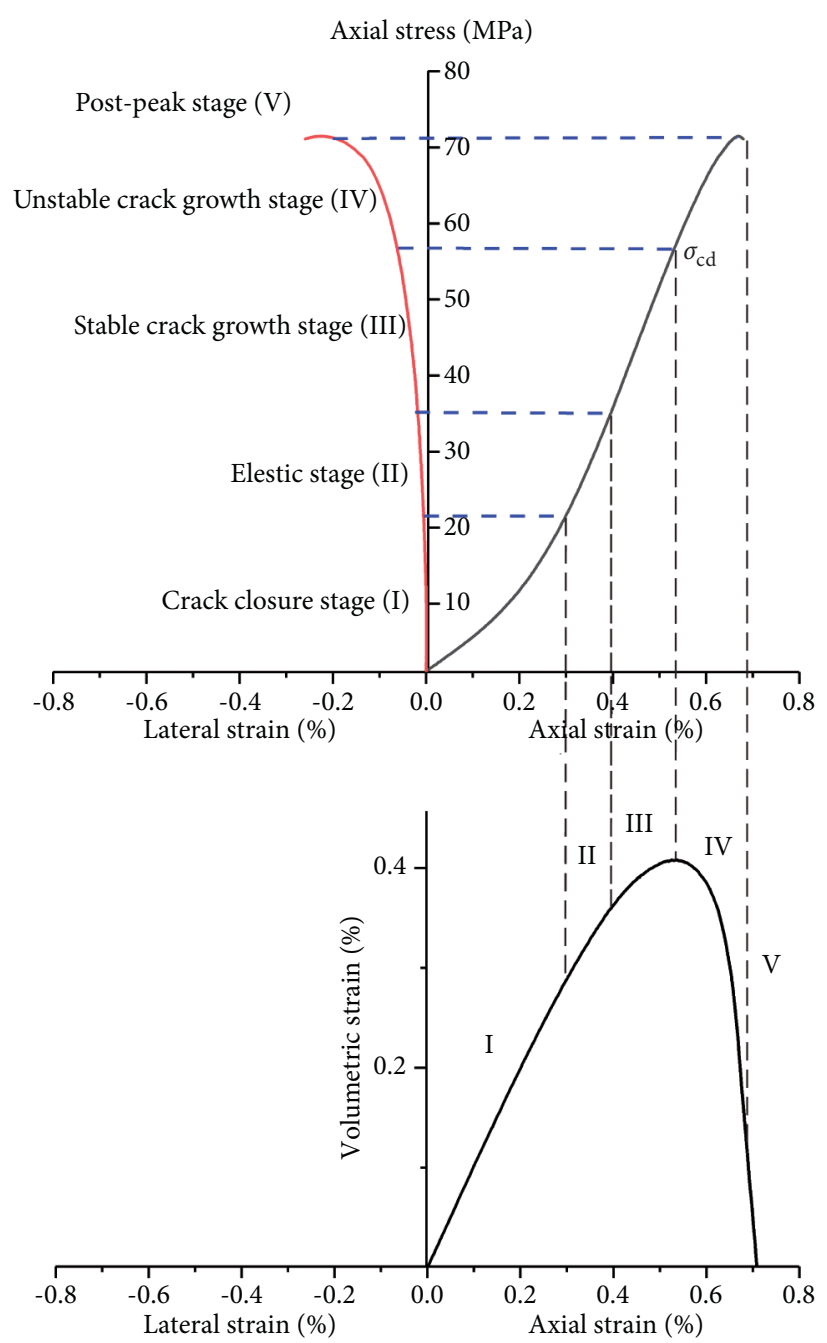

FIGURE 7: Stage division of rock failure process and schematic diagram of crack damage stress ( $\left.\sigma_{\mathrm{cd}}\right)$ (adapted from Martin et al. [19]).

stress, the crack grows unsteadily and begins to coalesce. Crack damage stress is one of the key stresses in rocks, which corresponds to the long-term rock strength $[19,20]$. The crack damage stress of a rock can be determined using the corresponding volume strain curve [21]. The relationship between the crack damage stress and cycle number is shown in Figure 8 . When the cycle number is less than 3 , the saturated phyllite does not change from compaction-dominated to expansion-dominated. The crack damage stress of the saturated phyllite cannot be obtained in this case. Similarly, when the cycle number is less than 7 , the crack damage stress of the dry phyllite cannot be obtained. As shown in Figure 8, with an increase in the number of cycles, the crack damage stress of phyllite first increases and then decreases. For example, when the confining pressure was $10 \mathrm{MPa}$, the crack damage stress of dry phyllite first increases from 90.78 to $139.60 \mathrm{MPa}$. Then, the crack damage stress decreases from 139.60 to $130.63 \mathrm{MPa}$. With the increase of confining pressure, the crack damage stress of phyllite increases. The crack damage stress of saturated phyllite is lower than that of dry phyllite. This shows that water accelerates the change of volume from compaction to expansion.
3.4. Energy Dissipation and Damage Variable. For energy dissipation central to deformation and failure of rock materials $[22,23]$, damage is a process of accumulating dissipated energy. Ignoring the damping effect of the test system, the total energy $(U)$ generated by the external force is transformed into elastic energy $\left(E_{\mathrm{e}}\right)$ and dissipative energy $\left(E_{\mathrm{d}}\right)$. The elastic energy is released during unloading and is approximately equal to the negative work $\left(E_{\mathrm{r}}\right)$ caused by the external force during unloading (Figure 9):

$$
U=E_{\mathrm{e}}+E_{\mathrm{d}}=E_{\mathrm{r}}+E_{\mathrm{d}},
$$

where $U$ is the total energy, $E_{\mathrm{e}}$ is the elastic energy, $E_{\mathrm{d}}$ is the dissipated energy, and $E_{\mathrm{r}}$ is the negative work done by the external force during unloading.

As shown in Figure 9, the area of the figure surrounded by "ABCF" represents the total input energy $(U)$, while the area surrounded by "CDEF" represents the negative work $\left(E_{\mathrm{r}}\right)$ caused by the axial stress during unloading, which is approximately equal to the elastic energy $\left(E_{\mathrm{e}}\right)$. The area surrounded by "ABCDE" represents the energy dissipated $\left(E_{\mathrm{d}}\right)$ during one cyclic loading and unloading. The area 


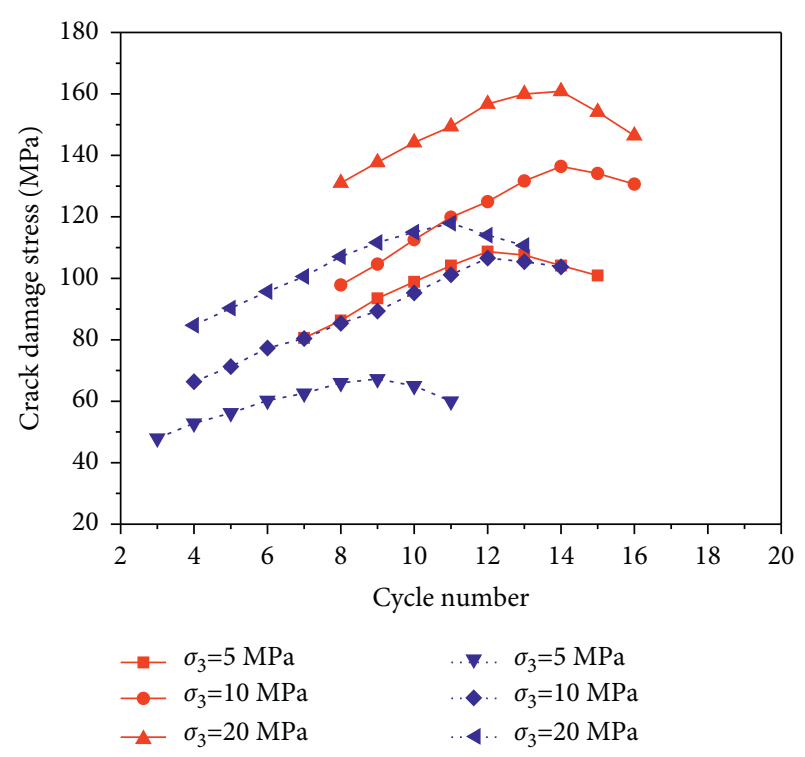

Figure 8: Relationship between crack damage stress and cycle number (blue denotes saturated phyllite and red denotes dry phyllite; $\sigma_{3}$ is the confining pressure).

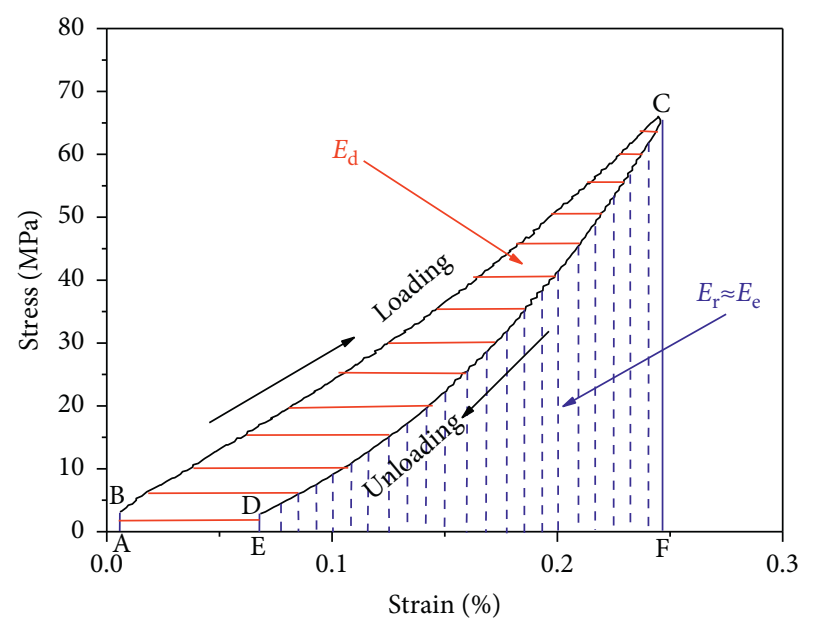

FIGURE 9: Schematic diagram of energy calculation during one cyclic loading and unloading.

surrounded by axial stress-strain curve can be calculated using calculus [24]. The accumulated dissipated energy $\left(E^{*} \mathrm{~d}\right)$ is equal to the sum of the dissipated energy $\left(E_{\mathrm{d}}\right)$ of each cycle. As shown in Figure 10, the relationship between the cumulative dissipated energy $\left(E^{*} \mathrm{~d}\right)$ and axial stress can be expressed as

$$
E_{\mathrm{d}}^{*}=m \exp \left(n \sigma_{1}\right)
$$

where $E^{*} d$ is the accumulated dissipated energy, $m$ and $n$ are fitting parameters, and $\sigma_{1}$ is the axial stress.

The cumulative dissipated energy $\left(E^{*} \mathrm{~d}\right)$ increases exponentially with an increase in axial stress (Figure 10).

To study the damage evolution of rocks under cyclic loading conditions, Peng et al. [24] proposed an expression for damage variable:

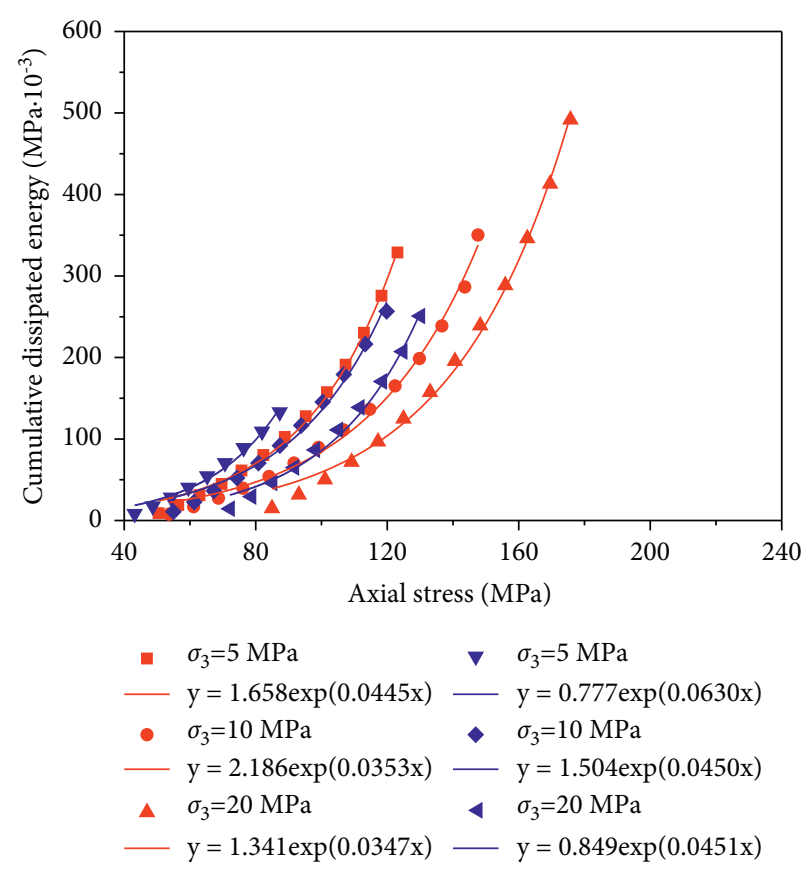

FIGURE 10: The relationship between cumulative dissipated energy and axial stress (blue denotes saturated phyllite and red denotes dry phyllite; $\sigma_{3}$ is the confining pressure).

$$
D=\frac{2}{\pi} \arctan \frac{E_{\mathrm{d}}^{*}}{\sigma_{1}}
$$

where $D$ is the damage variable, $E^{*} d$ is the accumulated dissipated energy, and $\sigma_{1}$ is the axial stress.

According to (2)-(3), we modify the damage variable $D$. The new damage variable $\left(D_{\mathrm{p}}\right)$ of phyllite can be expressed as

$$
D_{\mathrm{p}}=\frac{2}{\pi} \arctan \frac{m \exp \left(n \sigma_{1}\right)}{\sigma_{1}} .
$$

The damage variables of the saturated and dry phyllite were calculated according to (4). As shown in Figure 11, with the increase of axial stress, the damage variables of saturated and dry phyllite increase in an S-shape. The confining pressure and water have obvious effects on the damage variable. When the axial stresses are the same, the lower the confining pressure, and the larger the damage variable. This shows that the confining pressure can inhibit damage to phyllite. When the confining pressures are the same, the damage variable of saturated phyllite is larger than that of dry phyllite, as water aggravates the damage to phyllite. However, the evolution trend of the damage variable is unrelated to the confining pressure and water. There is a critical value for damage variable $\left(D_{0}\right)$. When $D_{\mathrm{p}}$ is larger than $D_{0}$, the phyllite sample is destroyed. The critical damage variables of the dry and saturated phyllite samples are between 0.745 and 0.841 , with an average value of 0.80 . The critical damage variable is independent of the confining pressure and water. This shows that the damage variable proposed in this paper is reasonable and can be used as an index to predict the failure of phyllite. 


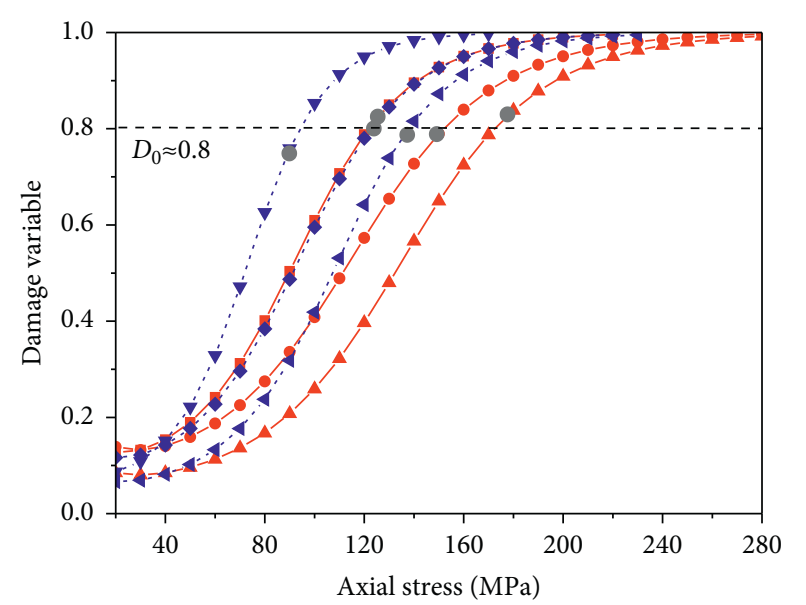

- Phyllite failure point

$$
\begin{array}{ll}
-\sigma_{3}=5 \mathrm{MPa} & \rightarrow \sigma_{3}=5 \mathrm{MPa} \\
-\bullet \sigma_{3}=10 \mathrm{MPa} & \multimap-\sigma_{3}=10 \mathrm{MPa} \\
-\downarrow-\sigma_{3}=20 \mathrm{MPa} & \multimap-\sigma_{3}=20 \mathrm{MPa}
\end{array}
$$

FIgURE 11: The relationship between the damage variable and axial stress (blue denotes saturated phyllite and red denotes dry phyllite; $\sigma_{3}$ is the confining pressure; $D_{0}$ is the critical damage variable).

3.5. Failure Mode. Failure mode is an important research topic in rock mechanics. Under triaxial cyclic loading conditions, the failure modes of the dry and saturated specimens are shear failures (Figures 12-13). The angle between the fracture plane and the horizontal plane is the fracture angle $(\alpha)$ 。 When the confining pressure increases from 5 to $20 \mathrm{MPa}$, the fracture angle decreases from $68^{\circ}$ to $53^{\circ}$. The fracture angle of phyllite decreases with the increase of confining pressure.

The fracture surfaces of phyllite under cyclic loading are shown in Figures 14-15. When the confining pressure is low $\left(\sigma_{3}=5 \mathrm{MPa}\right)$, the $\mathrm{U}$-shaped fractures are rough and uneven; furthermore, there are obvious slip marks and a significant amount of powder on the U-shaped fractures. This indicates that a large number of mineral particles slide and rotate on the shear plane, and the dilatancy effect is strong. With the increase of confining pressure $\left(\sigma_{3}=10,20 \mathrm{MPa}\right)$, the $\mathrm{U}$-shaped fractures become smooth. There is a small amount of rock powder on the shear plane, and the dilatancy effect is weakened.

\section{Discussion}

4.1. Degradation Mechanism of Water-Saturated Phyllite. Phyllite is a type of water-sensitive rock. In this paper, the deterioration mechanism of water-saturated phyllite is discussed from two aspects: microstructure and micromechanics.

4.1.1. Damage to Microstructure. Phyllite contains clay minerals. During the saturation process, these minerals undergo swelling, nonuniform deformation, and shedding. To better analyze the changes in the microstructure of saturated phyllite, the dry and saturated phyllite were analyzed using scanning electron microscopy. Figure 16(a) shows that the surfaces of the clay minerals are flat and smooth. The boundary of mineral particle is clear. Most of the clay minerals are in surface-to-surface contact and are some local microcracks. After water saturation (Figure 16(b)), the boundary between the mineral particles becomes blurred owing to the swelling deformation of the clay minerals and the dissolution of cement. Flaky clay minerals soften and shed, and the exfoliated material decomposes into small particles that adhere to the surfaces of large mineral particles. In a saturated state, the contact relationship between clay minerals gradually changes to point-to-surface contact. The structure of the samples tends to be loose, which leads to the deterioration of the saturated phyllite. In addition, the hydrolysis of quartz and the dissolution of calcite are also important factors for the degradation of phyllite. During saturation process, the microcracks are filled with free water. The crack tip is the most active area of the water-rock reaction [25]. Because of hydrolysis, the strong $\mathrm{Si}-\mathrm{O}-\mathrm{Si}$ bond is replaced by the weak $\mathrm{Si}-\mathrm{OH}$ bond, which reduces the growth barrier and fracture toughness of microcracks $[26,27]$. The mechanical properties of phyllite are further degraded. The reaction formulas can be expressed as

$$
\begin{array}{r}
(-\mathrm{Si}-\mathrm{O}-\mathrm{Si}-)+(\mathrm{H}-\mathrm{O}-\mathrm{H}) \longrightarrow(-\mathrm{Si}-\mathrm{OH}-\mathrm{HO}-\mathrm{Si}-) \\
\mathrm{CaCO}_{3}+\mathrm{CO}_{2}+\mathrm{H}_{2} \mathrm{O} \longrightarrow 2 \mathrm{HCO}_{3}^{-}+\mathrm{Ca}^{2+}
\end{array}
$$

The physical and chemical reactions of clay minerals, quartz, and calcite with water damage the microstructure; this process is the basic factor for the deterioration of saturated phyllite.

4.1.2. Micromechanical Analysis. To study the effect of water on crack propagation, the sliding crack model [28] was used to analyze a single microcrack without considering the interaction between cracks (Figure 17). During the saturation process, the volume of clay minerals expands significantly, while the volume of quartz and feldspar remains almost unchanged, which leads to nonuniform expansion stress in phyllite. The expansion stress $\left(P_{\text {ew }}\right)$ can not only promote the propagation of the original cracks but also produce new microcracks. In addition to expansion stress, pore water pressure $\left(P_{\mathrm{pw}}\right)$ may be another factor affecting the mechanical properties of phyllite. The pore water pressure is related not only to the volume deformation of the rock but also to the crack propagation rate. During volume compression, the pore water pressure increases with the increase of cyclic load. When the pore water pressure exceeds the tensile strength of the rock, it causes the propagation of microcracks [29]. During the volume expansion, the pore water pressure in a crack is mainly related to the distribution of water. Under triaxial cyclic loading conditions, the propagation speed of the crack is slow; free water can reach the crack tip in time $[26,30]$. The free water at the crack tip will produce a water wedge effect and promotes crack 


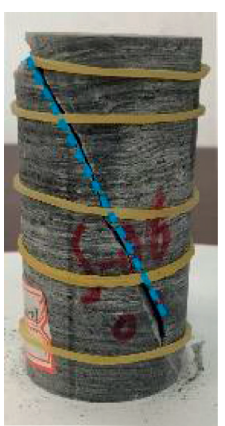

(a)

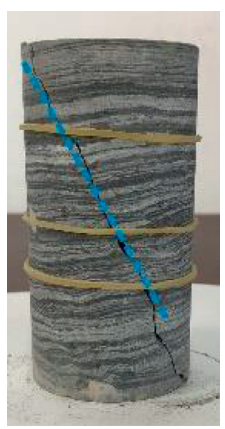

(b)

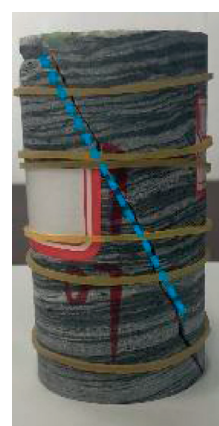

(c)

FiguRE 12: Failure modes of dry phyllite ( $\sigma_{3}$ is the confining pressure; $\alpha$ is the fracture angle) (a) $\sigma_{3}=5 \mathrm{MPa}, \alpha=64^{\circ}$; (b) $\sigma_{3}=10 \mathrm{MPa}, \alpha=62^{\circ}$; and (c) $\sigma_{3}=20 \mathrm{MPa}, \alpha=61^{\circ}$.

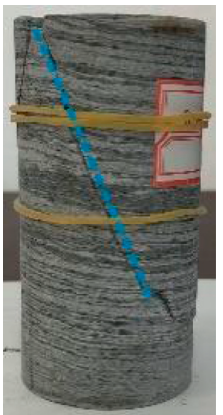

(a)

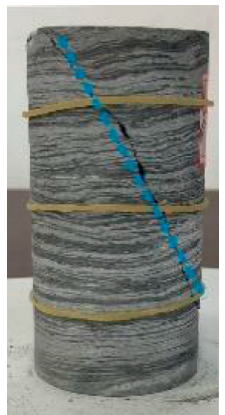

(b)

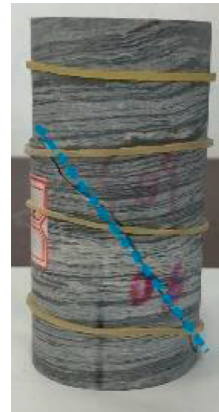

(c)

FIGURE 13: Failure modes of saturated phyllite ( $\sigma_{3}$ is the confining pressure; $\alpha$ is the fracture angle) (a) $\sigma_{3}=5 \mathrm{MPa}, \alpha=68^{\circ}$; (b) $\sigma_{3}=10 \mathrm{MPa}$, $\alpha=62^{\circ}$; and (c) $\sigma_{3}=20 \mathrm{MPa}, \alpha=53^{\circ}$.

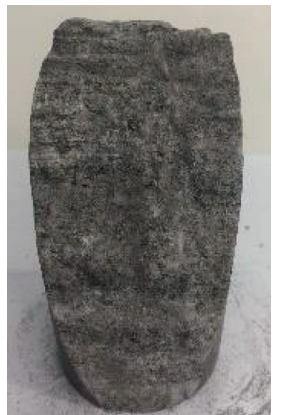

(a)

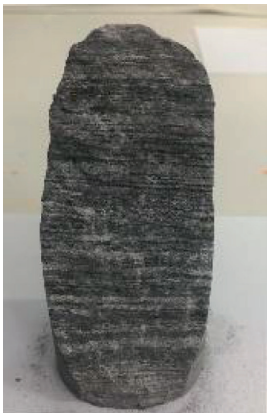

(b)

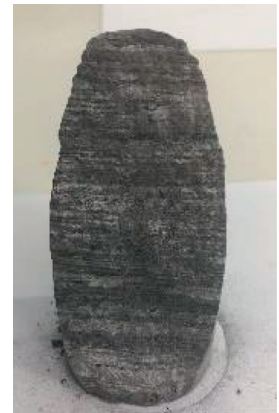

(c)

FIGURE 14: U-shaped fractures of dry phyllite specimens ( $\sigma_{3}$ is the confining pressure). (a) $\sigma_{3}=5 \mathrm{MPa}$, (b) $\sigma_{3}=10 \mathrm{MPa}$, and (c) $\sigma_{3}=20 \mathrm{MPa}$.

expansion [31]. In addition, (6) shows that pore water pressure $\left(P_{\mathrm{pw}}\right)$ and expansion stress $\left(P_{\mathrm{ew}}\right)$ can also reduce the effective normal stress $\left(\sigma_{\mathrm{w}}\right)$ on the main crack, which promotes crack expansion and reduces the strength of phyllite. Under saturated conditions, the degree of loss of the friction coefficient of different minerals varies greatly. Quartz and feldspar have poor hydrophilicity; thus, the friction coefficients of quartz and feldspar do not change significantly [32]. This is because the surface charges of quartz and feldspar are mostly neutral. There is little binding water on the particle surface; therefore, water has little effect on the friction coefficient of nonadsorbable minerals such as feldspar and quartz. However, the friction coefficients of illite, mica, chlorite, and other clay minerals decreases by $20-60 \%$ [32], which leads to the increase of the effective shear stress $\left(\tau_{\mathrm{w}}\right)$ on the main crack (see (7)). This further promotes crack expansion and reduces the strength of phyllite. 


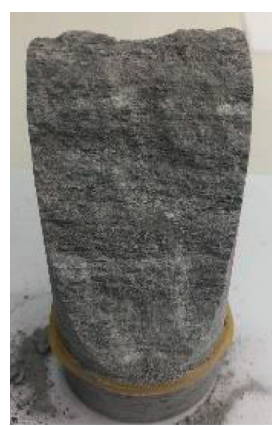

(a)

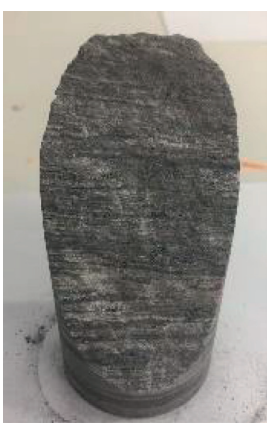

(b)

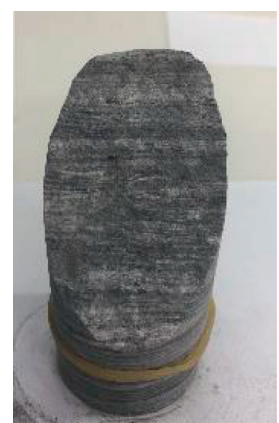

(c)

FIGURE 15: U-shaped fractures of saturated phyllite specimens ( $\sigma_{3}$ is the confining pressure) (a) $\sigma_{3}=5 \mathrm{MPa},(\mathrm{b}) \sigma_{3}=10 \mathrm{MPa}$, and (c) $\sigma_{3}=20 \mathrm{MPa}$.
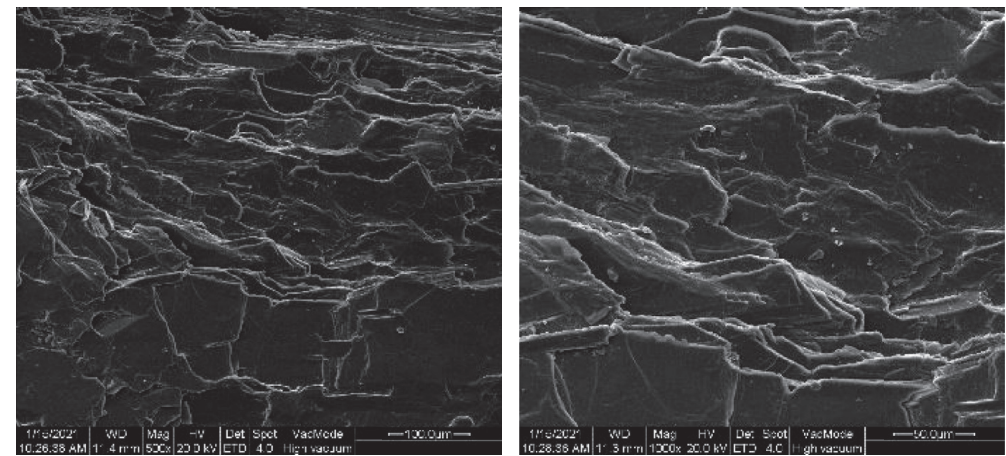

(a)
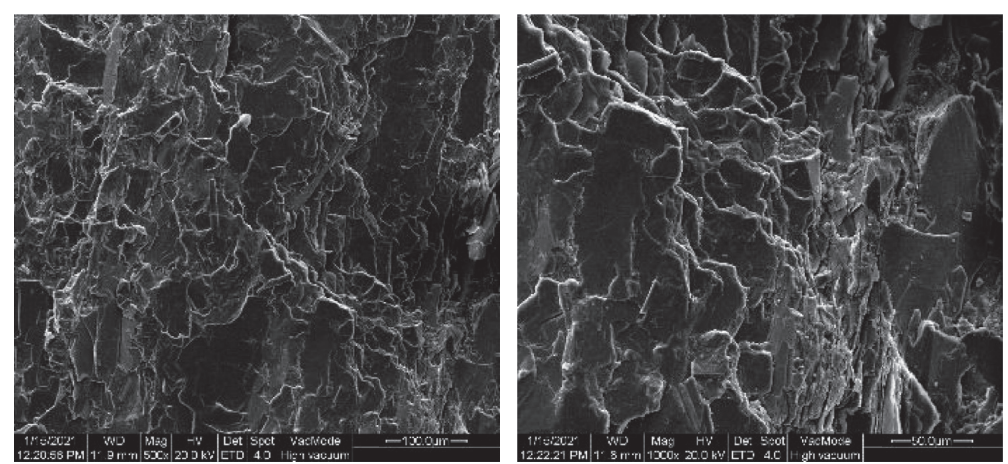

(b)
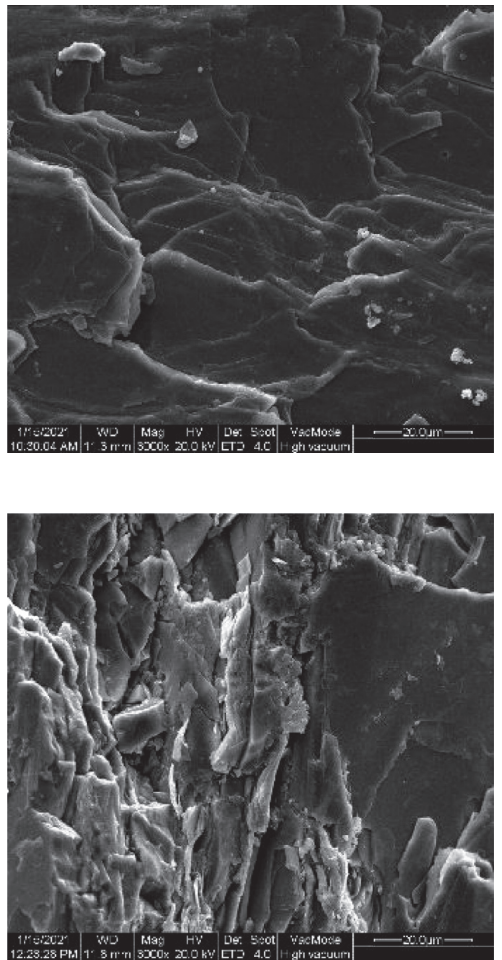

FIGURE 16: Scanning electron microscopy (SEM) photographs of phyllite: (a) dry phyllite and (b) saturated phyllite.

The effective normal stress $\left(\sigma_{\mathrm{w}}\right)$ and the effective shear stress $\left(\tau_{\mathrm{w}}\right)$ of the main crack can be approximately expressed as [33]

$$
\begin{aligned}
& \sigma_{\mathrm{w}}=\frac{1}{2}\left[\left(\sigma_{1}+\sigma_{3}\right)+\left(\sigma_{1}-\sigma_{3}\right) \cos 2 \theta\right]-\left(P_{\mathrm{p} w}+P_{\mathrm{ew}}\right), \\
& \tau_{\mathrm{w}}=\frac{1}{2}\left(\sigma_{1}-\sigma_{3}\right) \sin 2 \theta-\mu_{\mathrm{w}} \sigma_{\mathrm{w}},
\end{aligned}
$$

where $\sigma_{1}$ is the axial compressive stress, $\sigma_{3}$ is the confining pressure, $P_{\mathrm{pw}}$ is the pore water pressure, $P_{\mathrm{ew}}$ is expansion force, the angle between the main crack and the horizontal axis is $\theta$, $\sigma_{\mathrm{w}}$ is the effective normal stress, $\tau_{\mathrm{w}}$ is the effective shear stress, and $\mu_{\mathrm{w}}$ is the friction coefficient of the water-bearing crack.
4.2. Energy Release and Crack Distribution Characteristics of Water-Saturated Phyllite. During the cyclic loading process, $\mathrm{AE}$ signals can directly reflect the damage process of phyllite. The axial stress-time-AE energy curves of the phyllite are shown in Figure 18. The AE energy of phyllite can be divided into two modes. The first mode is the cluster mode. In this mode, during the early cyclic loading, the AE energy is very small, and the cumulative $\mathrm{AE}$ energy curve is relatively stable. However, during the last 1-2 cycles, the AE energy increases rapidly and distributes intensively. The AE energy of dry phyllite belongs to the cluster mode. This shows that there is little AE energy in the prepeak stage, and the input energy is almost all transformed into elastic energy. When the dry phyllite approaches failure, the accumulated energy 


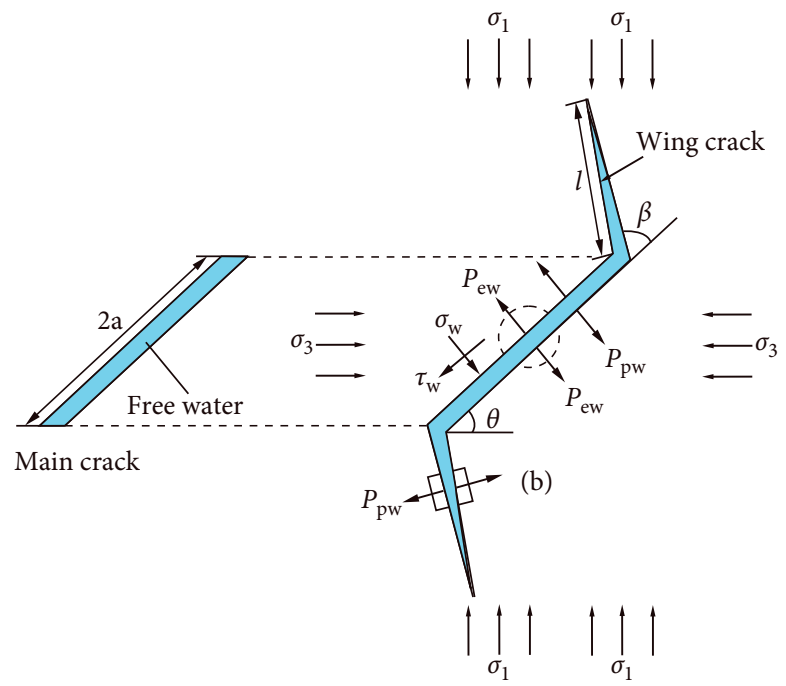

FIgURE 17: Sliding crack model.

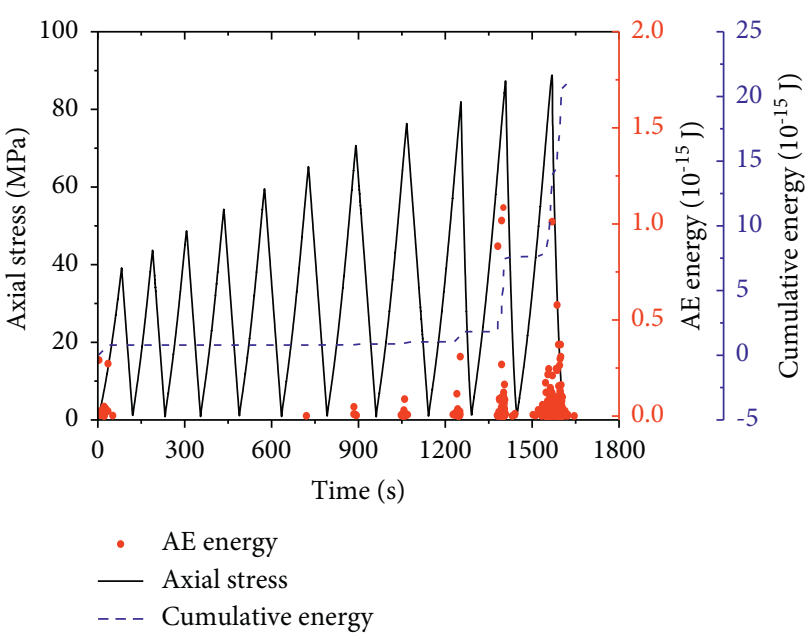

(a)

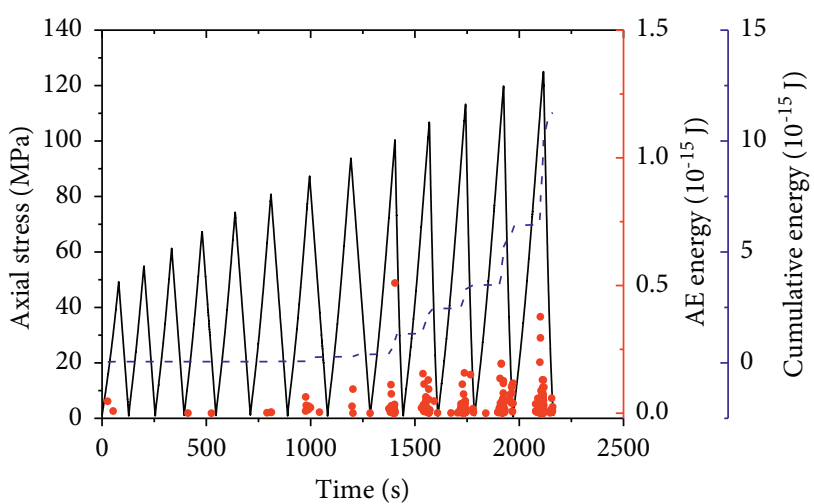

- AE energy

- Axial stress

- - - Cumulative energy

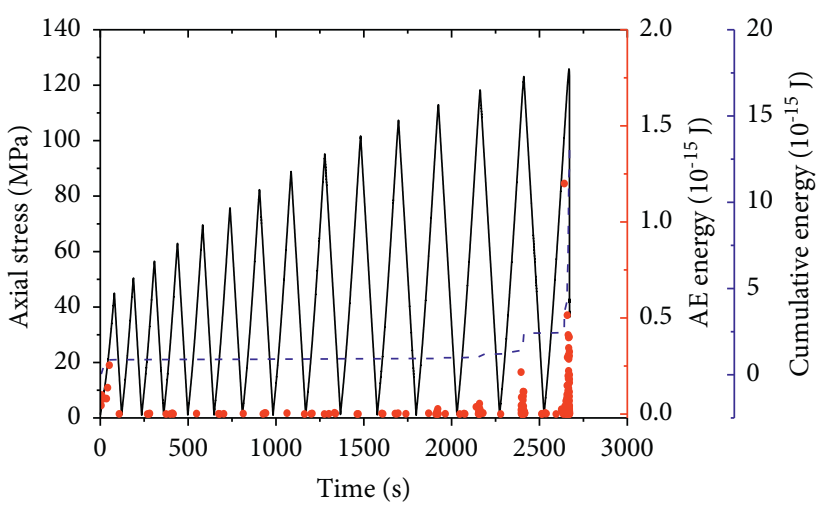

- AE energy

- Axial stress

- - - Cumulative energy

(b)

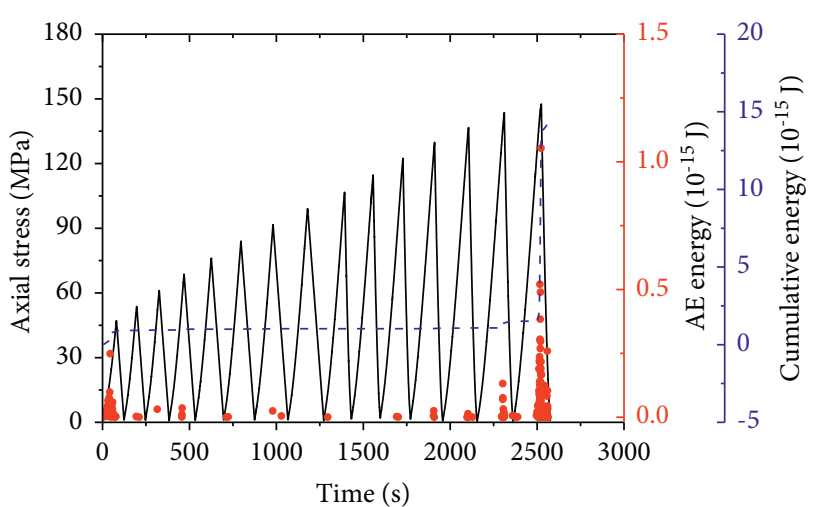

- AE energy

— Axial stress

- - - Cumulative energy

(c)

(d)

Figure 18: Continued. 


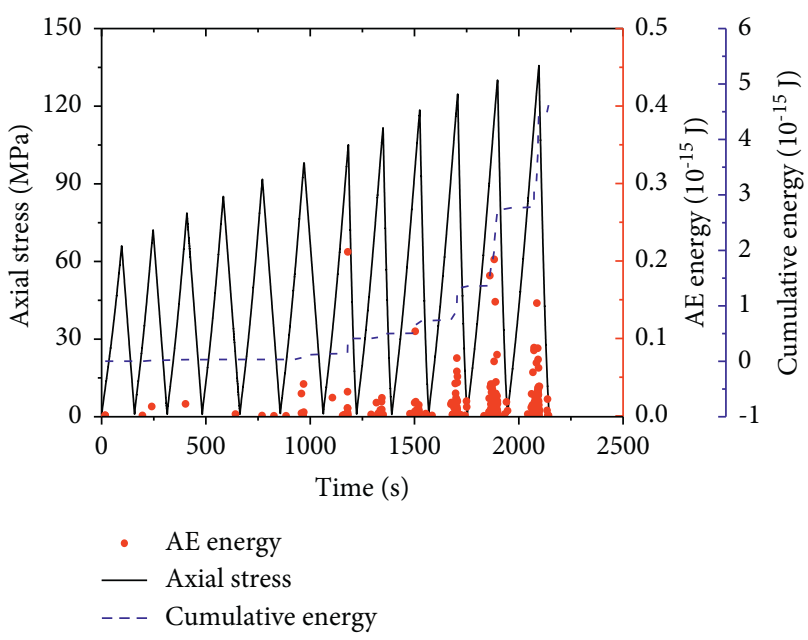

(e)

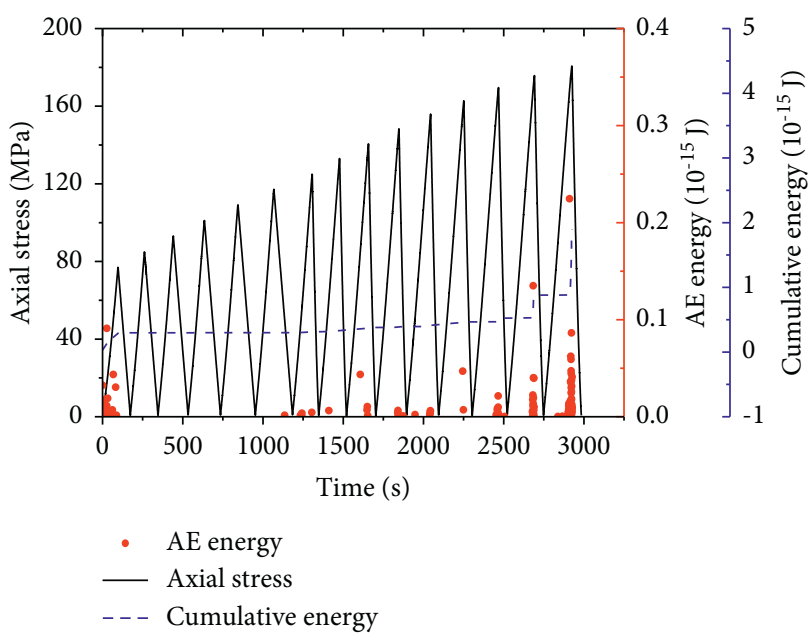

(f)

Figure 18: The axial stress-time-AE energy curves of phyllite ( $\sigma_{3}$ is the confining pressure). (a) Saturated sample, $\sigma_{3}=5 \mathrm{MPa}$. (b) Dry sample, $\sigma_{3}=5 \mathrm{MPa}$. (c) Saturated sample, $\sigma_{3}=10 \mathrm{MPa}$. (d) Dry sample, $\sigma_{3}=10 \mathrm{MPa}$. (e) Saturated sample, $\sigma_{3}=20 \mathrm{MPa}$. (f) Dry sample, $\sigma_{3}=20 \mathrm{MPa}$.

is rapidly released to form macro fracture plane. High-energy rupture events can be detected when only failure occurs. The second mode is the multipeak mode, which includes several peaks of AE energy during loading and unloading. Moreover, the cumulative energy curve exhibits obvious steps. The AE energy of saturated phyllite belongs to the multipeak mode (Figure 18). During the early cyclic loading (compaction and elastic stages), there is little difference in AE energy between saturated phyllite and dry phyllite. However, with the increase of cycles (plastic stage), the saturated phyllite produces a large number of AE energy by sliding friction. This indicates that water reduces the energy required for breakdown and promotes the sliding of shear cracks. The damage stress of saturated phyllite decreases. Therefore, the damage of water-saturated phyllite occurs at a lower stress level, and the microcracks initiate and expand continuously during cyclic loading. The AE energy curve of saturated phyllite exhibits obvious steps before failure, and high-energy shear rupture events can be detected repeatedly.

The evolution of AE events with axial stress is shown in Figures 19-20. Under early cyclic loading conditions (compaction and elastic stages), fewer AE events occur. The AE events mainly consist of the closure of primary cracks. With the increase of axial stress (more than $0.7 \sigma_{\mathrm{c}}$ ), the crack distribution characteristic of saturated phyllite becomes different from that of dry phyllite. Water reduces the strength of phyllite and accelerates the localization of damage. The cracks in saturated phyllite are relatively concentrated. There is an obvious nucleation region in the center of the saturated specimen (Figure 19). With the increase of cyclic loading, the nucleation region gradually diffuses from the center to the upper and lower ends of the specimen. However, there is no obvious nucleation area in the dry phyllite, and the microcracks are scattered (Figure 20). With the increase of cyclic loading, cracks increase sharply, forming a fracture zone.
4.3. Potential Application for the Engineering. With an increase in excavation depth, rock mass is inevitably affected by confining pressure and strong excavation disturbances, which induce a series of geological engineering hazards. When tunnels and slopes are excavated, the rock mass undergoes very complicated stress path owing to the layered, segmented excavation and excavation between adjacent caverns. The rock mass is in a state of cyclic loading and unloading. In addition, owing to the existence of water in engineering rock mass, the deformation and failure process of rocks become more complicated. The stability of rock mass is the key to engineering safety. In previous engineering applications, stability was evaluated on the basis of critical stress or deformation parameters. However, sometimes these parameters cannot reflect the actual damage of the rock mass under complex stress paths. For instance, the damage stresses and elastic modulus of phyllite first increased and then decreased under triaxial cyclic loading. Therefore, the appropriate damage variable is helpful to identify the actual damage in rock. The damage variable proposed in this paper can be used as an index to predict the failure of phyllite. According to the actual damage inside the rock, the reasonable and economical supporting schemes are adopted. Furthermore, AE can effectively monitor the internal damage of rock. It is helpful to explore the failure mechanism of rocks and provide a basis for disaster prevention. The results of this study reveal the AE energy release characteristics of dry and saturated phyllite during excavation, which can provide guidance for monitoring the deformation and damage of surrounding rock. In the process of excavation of the surrounding rock, waterbearing phyllite releases a lot of energy before failure and high-energy shear rupture events can be detected repeatedly. However, a large amount of AE energy and high-energy rupture events appear when only the dry phyllite approaches failure, which needs our special attention. 


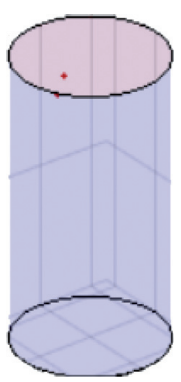

(1) $0.3 \sigma_{c}$

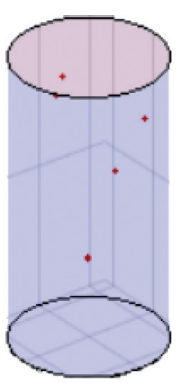

(2) $0.5 \sigma_{\mathrm{c}}$

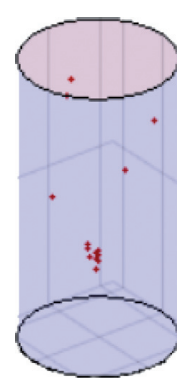

(3) $0.7 \sigma_{\mathrm{c}}$

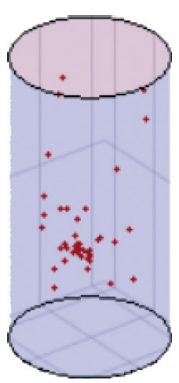

(4) $0.8 \sigma_{\mathrm{c}}$

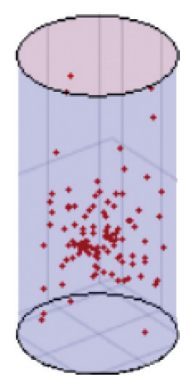

(5) $0.9 \sigma_{\mathrm{c}}$

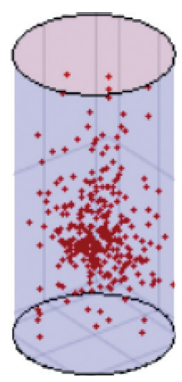

(6) $1.0 \sigma_{c}$

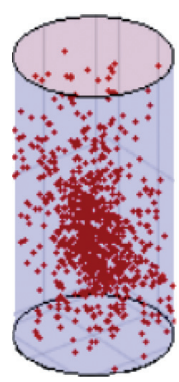

(7) Failure

FIGURE 19: Spatial distribution of AE events at different stress levels for saturated phyllite $\left(\sigma_{3}=20 \mathrm{MPa} ; \sigma_{\mathrm{c}}\right.$ is the peak stress). (a) $0.3 \sigma_{\mathrm{c}}$, (b) $0.5 \sigma_{\mathrm{c}}$, (c) $0.7 \sigma_{\mathrm{c}}$, (d) $0.8 \sigma_{\mathrm{c}}, € 0.9 \sigma_{\mathrm{c}}$, (f) $1.0 \sigma_{\mathrm{c}}$, and (g) failure.

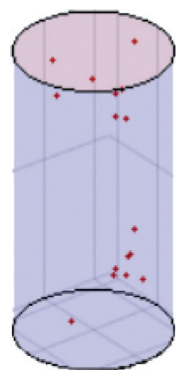

(1) $0.3 \sigma_{\mathrm{c}}$

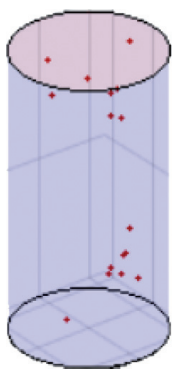

(2) $0.5 \sigma_{\mathrm{c}}$

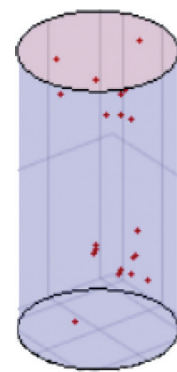

(3) $0.7 \sigma_{\mathrm{c}}$

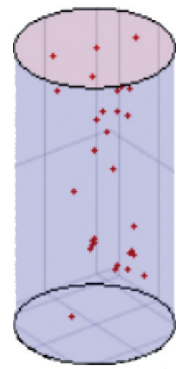

(4) $0.8 \sigma_{c}$

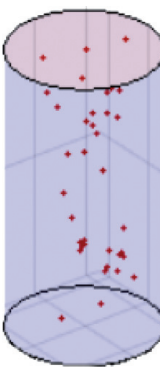

(5) $0.9 \sigma_{\mathrm{c}}$

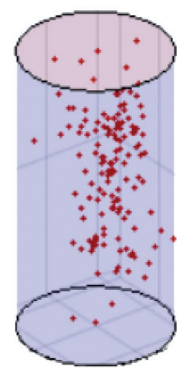

(6) $1.0 \sigma_{\mathrm{c}}$

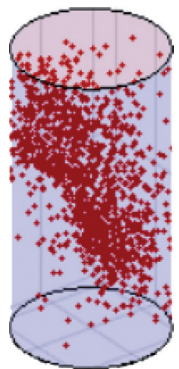

(7) Failure

Figure 20: Spatial distribution of AE events at different stress levels for dry phyllite ( $\sigma_{3}=20 \mathrm{MPa} ; \sigma_{\mathrm{c}}$ is the peak stress). (a) $0.3 \sigma_{\mathrm{c}}$, (b) $0.5 \sigma_{\mathrm{c}}$, (c) $0.7 \sigma_{\mathrm{c}}$, (d) $0.8 \sigma_{\mathfrak{c}}, € 0.9 \sigma_{\mathrm{c}}$, (f) $1.0 \sigma_{\mathrm{c}}$, and (g) failure.

\section{Conclusions}

In this study, we have carried out a series of triaxial cyclic tests on dry and water-saturated phyllite by employing the MTS 815 servohydraulic testing system and $\mathrm{AE}$ testing equipment. The deformation parameters, damage stress, damage variable, $\mathrm{AE}$ characteristics, and failure mode of phyllite under confining pressures of 5, 10, and $20 \mathrm{MPa}$ were analyzed. Degradation mechanism of water-saturated phyllite was discussed, and the energy release and crack distribution characteristics of phyllite was revealed. The main conclusions are as follows:

(1) Phyllite is a type of water-sensitive rock. The compressive strength, damage stress, and elastic modulus of saturated phyllite decrease, while the irreversible strain and Poisson's ratio of saturated phyllite increase. Water accelerates the change of volume from compaction to expansion.

(2) Stress path has an obvious influence on the deformation parameters of phyllite. The irreversible strain increases exponentially with the increase of axial stress. With the increase of cycles, the elastic modulus increases first, then tends to be constant, and then finally decreases. Poisson's ratio increases with the number of cycles. The crack damage stresses of phyllite specimens first increased and then decreased with an increase in the number of cycles.

(3) Based on the dissipated energy, a new damage variable $\left(D_{\mathrm{p}}\right)$ for phyllite was established. With the increase of axial stress, the damage variable of dry and saturated phyllite increases in an S-shape. The critical damage variable $\left(D_{0}\right)$ of phyllite is approximately 0.80 ; this variable can be used as an index to predict the failure of phyllite.

(4) The localization of damage is serious for saturated phyllite. The microcracks occur earlier and are relatively concentrated, and there is an obvious nucleation area. The AE energy curve exhibits obvious steps before failure, and high-energy shear rupture events can be detected repeatedly. The microcracks of dry phyllite are scattered. High-energy rupture events can be detected when only failure occurs.

(5) The water saturation effect of phyllite is obvious. The effective normal stress on the crack surface decreases and the shear stress increases under the influence of expansion stress, pore water pressure, and friction coefficient. Water promotes crack initiation and propagation, reduces the strength of phyllite, accelerates the localization of damage, and changes the AE energy release and crack distribution characteristics of the phyllite.

\section{Data Availability}

The data used to support the findings of the study are included within the article.

\section{Conflicts of Interest}

The authors declare no conflicts of interest. 


\section{Acknowledgments}

This work was supported by the Fundamental Research Funds for the Central Universities, CHD (300102260708), the National Natural Science Foundation of China (41831286 and 42041006), and the Transportation Construction Science and Technology Program of Sichuan Province (no. 2015A1-3).

\section{References}

[1] K. Fuenkajorn and D. Phueakphum, "Effects of cyclic loading on mechanical properties of Maha Sarakham salt," Engineering Geology, vol. 112, no. 1-4, pp. 43-52, 2010.

[2] H. Duan and Y. Yang, "Deformation and dissipated energy of sandstone under uniaxial cyclic loading," Geotechnical \& Geological Engineering, vol. 36, no. 1, pp. 611-619, 2017.

[3] Y. Liu, F. Dai, L. Dong, N. Xu, and P. Feng, "Experimental Investigation on the fatigue mechanical properties of intermittently jointed rock models under cyclic uniaxial compression with different loading parameters," Rock Mechanics and Rock Engineering, vol. 51, no. 1, pp. 47-68, 2018.

[4] J.-Q. Xiao, D.-X. Ding, F.-L. Jiang, and G. Xu, "Fatigue damage variable and evolution of rock subjected to cyclic loading," International Journal of Rock Mechanics and Mining Sciences, vol. 47, no. 3, pp. 461-468, 2010.

[5] J. Fan, J. Chen, D. Jiang, A. Chemenda, J. Chen, and J. Ambre, "Discontinuous cyclic loading tests of salt with acoustic emission monitoring," International Journal of Fatigue, vol. 94, pp. 140-144, 2017.

[6] Y. Sheng-Qi, P. G. Ranjith, and H. Yan-Hua, "Experimental investigation on mechanical damage characteristics of sandstone under triaxial cyclic loading," Geophysical Journal International, vol. 201, pp. 662-682, 2015.

[7] J. Ning, J. Wang, J. Jiang, S. Hu, L. Jiang, and X. Liu, "Estimation of crack initiation and propagation thresholds of confined brittle coal specimens based on energy dissipation theory," Rock Mechanics and Rock Engineering, vol. 51, no. 1, pp. 119-134, 2018.

[8] J. Singh, T. Ramamurthy, and G. V. Rao, "Strength anisotropies in rocks," Indian Geotechnical Journal, vol. 19, pp. 147-166, 1989.

[9] T. Ramamurthy, G. V. Rao, and J. Singh, "Engineering behaviour of phyllites," Engineering Geology, vol. 33, no. 3, pp. 209-225, 1993.

[10] Z. Q. Chen, C. He, D. Wu, W. L. Gan, G. W. Xu, and W. B. Yang, "Mechanical properties and energy damage evolution mechanism of deep-buried carbonaceous phyllite," Rock and Soil Mechanics, vol. 39, pp. 1-12, 2018.

[11] Y. S. Wu, Z. S. Tan, and Y. Yu, "Anisotropically mechanical characteristics of Maoxian group phyllite in northwest of Sichuan province," Rock and Soil Mechanics, vol. 39, pp. 207-215, 2018.

[12] G. Xu, C. He, A. Su, and Z. Chen, "Experimental investigation of the anisotropic mechanical behavior of phyllite under triaxial compression," International Journal of Rock Mechanics and Mining Sciences, vol. 104, pp. 100-112, 2018.

[13] A. Özbek, M. Gül, E. Karacan, and Ö. Alca, "Anisotropy effect on strengths of metamorphic rocks," Journal of Rock Mechanics and Geotechnical Engineering, vol. 10, no. 1, pp. 164-175, 2018.

[14] K. Hu, Q. Feng, and X. Wang, "Experimental research on mechanical property of phyllite tunnel surrounding rock under different moisture state," Geotechnical \& Geological Engineering, vol. 35, no. 1, pp. 303-311, 2017.

[15] G. Xu, C. He, Z. Chen, and A. Su, "Transverse isotropy of phyllite under Brazilian tests: laboratory testing and numerical simulations," Rock Mechanics and Rock Engineering, vol. 51, no. 4, pp. 1111-1135, 2018.

[16] F. Trippetta, C. Collettini, P. G. Meredith, and S. Vinciguerra, "Evolution of the elastic moduli of seismogenic Triassic Evaporites subjected to cyclic stressing," Tectonophysics, vol. 592, pp. 67-79, 2013.

[17] M. J. Heap and D. R. Faulkner, "Quantifying the evolution of static elastic properties as crystalline rock approaches failure," International Journal of Rock Mechanics and Mining Sciences, vol. 45, no. 4, pp. 564-573, 2008.

[18] M. J. Heap, S. Vinciguerra, and P. G. Meredith, "The evolution of elastic moduli with increasing crack damage during cyclic stressing of a basalt from Mt. Etna volcano," Tectonophysics, vol. 471, no. 1-2, pp. 153-160, 2009.

[19] C. D. Martin, R. Christiansson, and J. Soderhall, Rock Stability Considerations for Siting and Constructing a KBS-3 Repository. Based on Experiences from Aespoe HRL, AECL's URL, Tunneling and Mining [R], Swedish Nuclear Fuel and Waste Management Company, Stockholm, 2001.

[20] C. D. Martin, "Seventeenth Canadian Geotechnical Colloquium: the effect of cohesion loss and stress path on brittle rock strength," Canadian Geotechnical Journal, vol. 34, no. 5, pp. 698-725, 1997.

[21] M. Cai, P. K. Kaiser, Y. Tasaka, T. Maejima, H. Morioka, and M. Minami, "Generalized crack initiation and crack damage stress thresholds of brittle rock masses near underground excavations," International Journal of Rock Mechanics and Mining Sciences, vol. 41, no. 5, pp. 833-847, 2004.

[22] H. Xie, L. Li, R. Peng, and Y. Ju, "Energy analysis and criteria for structural failure of rocks," Journal of Rock Mechanics and Geotechnical Engineering, vol. 1, no. 1, pp. 11-20, 2009.

[23] P. Ruidong, Ju. Yang, J. G. Wang, H. P. Xie, F. Gao, and L. T. Mao, "Energy dissipation and release during coal failure under conventional triaxial compression," Rock Mechanics and Rock Engineering, vol. 48, pp. 509-526, 2015.

[24] R. D. Peng, J. Yang, and G. Feng, "Energy analysis on damage of coal under cyclical triaxial loading and unloading conditions," Journal of China Coal Society, vol. 39, pp. 245-252, 2014.

[25] G. H. Newman, "The effect of water chemistry on the laboratory compression and permeability characteristics of some North Sea Chalks," Journal of Petroleum Technology, vol. 35, no. 5, pp. 976-980, 1983.

[26] E. Cadoni, K. Labibes, C. Albertini, M. Berra, and M. Giangrasso, "Strain-rate effect on the tensile behaviour of concrete at different relative humidity levels," Materials and Structures, vol. 34, no. 1, pp. 21-26, 2001.

[27] S. W. Freiman, "Effects of chemical environments on slow crack growth in glasses and ceramics," Journal of Geophysical Research: Solid Earth, vol. 89, no. B6, pp. 4072-4076, 1984.

[28] H. Horii and S. Nemat-Nasser, "Brittle failure in compression: splitting, faulting and brittle-ductile transition," Philosophical Transactions of the Royal Society of London, vol. 319, pp. 337-374, 1986.

[29] C. L. Zhong, Z. Y. Zhang, G. R. Pathegama, Y. Y. Lua, and C. Xavier, "The role of pore water plays in coal under uniaxial cyclic loading," Engineering Geology, vol. 257, pp. 105-125, 2019. 
[30] P. Rossi and C. Boulay, "Influence of free water in concrete on the cracking process," Magazine of Concrete Research, vol. 42, no. 152, pp. 143-146, 1990.

[31] Z. Zhou, X. Cai, D. Ma et al., "Water saturation effects on dynamic fracture behavior of sandstone," International Journal of Rock Mechanics and Mining Sciences, vol. 114, pp. 46-61, 2019.

[32] C. A. Morrow, D. E. Moore, and D. A. Lockner, "The effect of mineral bond strength and adsorbed water on fault gouge frictional strength," Geophysical Research Letters, vol. 27, no. 6, pp. 815-818, 2000.

[33] M. F. Ashpy and S. M. Hallam, "The failure of brittle solids containing small cracks under compressive stress states," Acta Metallurgica, vol. 34, pp. 497-510, 1986. 